\title{
SEISMICITY NEAR PALMDALE, CALIFORNIA, AND ITS RELATION TO STRAIN CHANGES
}

\author{
Jeanne Sauberl, Karen McNally ${ }^{2}$, James C. Pechmann and Hiroo Kanamori
}

Seismological Laboratory, California Institute of Technology, Pasadena, California 91125

\begin{abstract}
We evaluate the relationships between the spatio-temporal patterns and faulting mechanisms of small earthquakes and the recent temporal changes in horizontal strain observed along the 'big bend' portion of the San Andreas fault near Palmdale, California. Microearthquake activity along the entire big bend of the San Andreas fault increased in November 1976 concurrent with the initiation of an earthquake swarm at Juniper Hills. This activity then decreased abruptly to the northwest and southeast of Juniper Hills during the beginning of 1979. This drop in seismic activity occurred around the time that crustal dilatation was observed on the U. S. Geological Survey Palmdale trilateration network. Focal mechanisms from the study region are predominantly thrust. There are two time periods when the mechanisms are closer to strike slip than to thrust. The first period (December 1976 to February 1977) corresponds to the beginning of the Juniper Hills swarm. The second period (November 1978 to April 1979) approximately coincides with a change in trend of the strain data from uniaxial $\mathrm{N}-\mathrm{S}$ compression to dilatation.
\end{abstract}

\section{Introduction}

The California Institute of Technology mobile trailer array of seven seismographic trailers was operated along the big bend portion of the San Andreas fault from October 1976 to August 1978 and from February 1980 through the present (December 1981). With the additional trailer coverage supplementing the permanent array (SCARLET) operated by the U. S. Geological Survey (USGS) and the California Institute of Technology along this section of the San Andreas fault, patterns in microearthquake activity can be better documented and focal mechanisms can be better constrained. The big bend portion of the San Andreas fault is important because of its known capability for rupture in great earthquakes such as the 1857 Fort Tejon earthquake of magnitude $8+$. . We have examined the patterns in seismicity since the initiation of the Juniper Hills swarm (November 1976, McNally et al. [1978]) and have determined focal mechanisms of some of the larger events $\left(M_{L} \geqslant 2.0\right)$ in this area for comparison with the horizontal strain measured on the USGS Palmdale trilateration network (hereafter referred to as

\footnotetext{
${ }^{1}$ Now at Department of Earth and Planetary Sciences, Massachusetts Institute of Technology, Cambridge, Massachusetts 02139.

${ }^{2}$ Now at Earth Sciences Board, University of California at Santa Cruz, Santa Cruz, California 95064.
}

Copyright 1983 by the American Geophysical Union.

Paper number 2B1394.

$0148-0227 / 83 / 002 B-1394 \$ 05.00$ the Palmdale net) [Savage et a1., 1981b]. Our objective is to understand better the relationship between seismicity and temporal changes in crustal deformation in the big bend region of the San Andreas fault.

\section{Seismicity}

Epicenters of all earthquakes located by the California Institute of Technology for October 1 , 1975, to October 31,1981 , which occurred along and adjacent to the San Andreas fault from $70 \mathrm{~km}$ south of Cajon Pass to Tejon Pass are shown in Figure 1. The 1975-1977 and 1979-1981 earthquake catalogs from the Caltech Seismological Laboratory are still preliminary, so hypocentral locations are subject to slight modification and magnitude determinations for the smaller events are incomplete.

To summarize the patterns of seismicity in time and in space for this time period, the microearthquakes were projected onto a line parallel to the San Andreas fault (Figure 2). The area used for this time/distance projection is shown in Figure 1. In November 1976 an increase in the number of small earthquakes of local magnitude between 2.0 and 3.0 began in the Juniper Hills region [McNa11y et al., 1978]. During 1976, 1977, and 1978 the microearthquake activity in the swarm area was accompanied by scattered activity along the entire San Andreas fault zone from Tejon Pass to Cajon Pass. At the beginning of 1979, microearthquake activity to the northwest and southeast of the Juniper Hills area abruptly decreased. This decrease in activity is roughly concurrent with the beginning of a time period of crustal dilatation inferred from ARIES data (P. F. MacDoran et al., unpublished data, 1980) and from the Palmdale network data [Savage et al., 1981b]. The decreased level of activity, particularly in the Lake Hughes region, continued through October 1980, well past the time period when dilatation was initially observed. In November 1980, microearthquake activity again increased along the entire big bend of the San Andreas fault.

For the time period of November 1, 1976, through october 31,1981 , it appears that the occurrence of larger events $\left(\mathrm{M}_{\mathrm{L}} \geqslant 2.5\right)$ which initiated in a small cluster in the Juniper Hills region migrated to the southeast, with an apparent velocity of approximately $6 \mathrm{~km} / \mathrm{yr}$. Bilateral migration of smaller events $\left(M_{L}>0.0\right)$ to the southeast and the northwest was noted by Drowley and McNally [1980] for the 2-year period following the initiation of the swarm. They reported a migration velocity of approximately $15 \mathrm{~km} / \mathrm{yr}$.

To examine more closely the temporal fluctuations in microearthquakes, we plotted the number of events which occurred in boxes $A$ and $B$ per 6-month period from October 1, 1975, to September 30, 1981 (Figure 3). Additionally, for each 6 -month time period the number of events per 
OCT. $1,1975-$ OCT. 31,1981

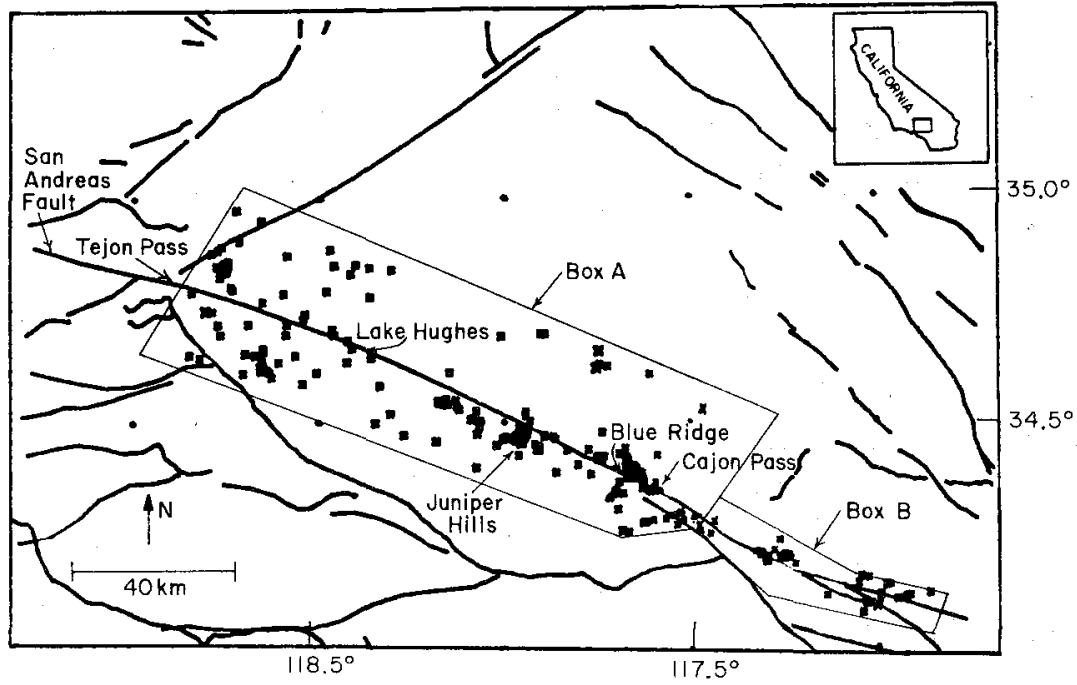

Fig. 1. Earthquakes located by the Calffornia Institute of Technology from October 1, 1975, to October 31, 1981, which occurred along and adjacent to the San Andreas fault in boxes $A$ and $B$. These boxes indicate the area used for time/distance projections. Box $B$ is more confined due to the fault complexity in that area.

$1 / 2$ unit $M_{T}$ magnitude is given. Events to which $M_{L}$ has not been assigned are given a $M_{L}$ of 0.0 . Examination of the plot of the number of events per 6 months shows an increase in activity (October 1, 1976 to March 31, 1979), followed by a lower level of activity (April 1, 1979 to
September 30,1980$)$, and then by an abrupt increase in activity (October 1,1980 to September 30, 1981). The increase in microearthquake activity which began in November 1980 coincides in time with an episode of $\mathrm{N}-\mathrm{S}$ and $\mathrm{E}-\mathrm{W}$ compression on the Palmdale net.

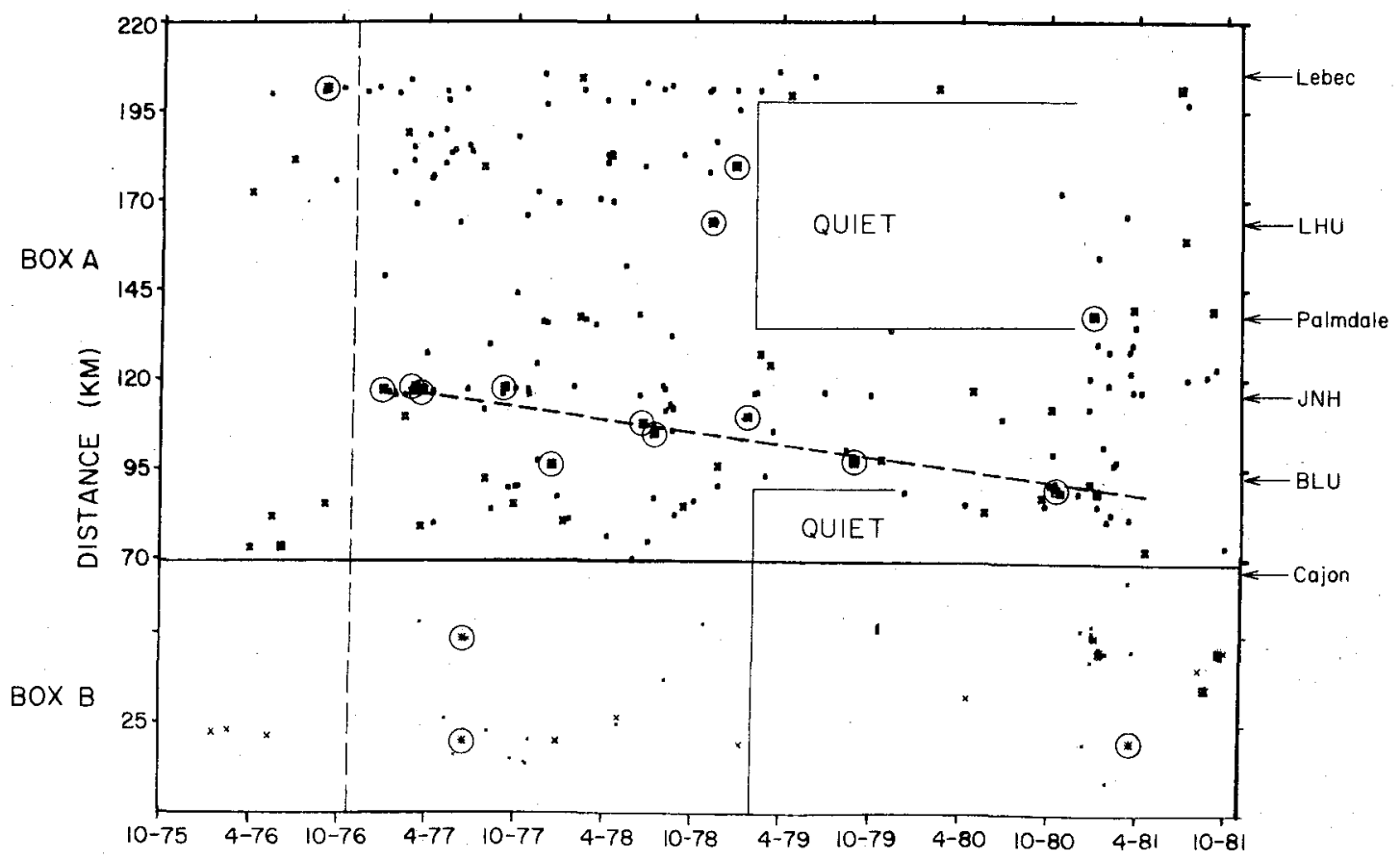

Fig. 2. Time/distance plot of seismicity for October 1, 1975, to October 31, 1981. The vertical, dashed line represents the initiation of the Juniper Hills swarm. The apparent migration of the larger events is suggested by the dashed line of slope 6 $\mathrm{km} / \mathrm{yr}$. Box A and box B are as given in Figure 1. Small crosses indicate events of $M_{I}<2.0$, large crosses indicate events of $2.0 \leqslant M_{L}<2.5$, and circled asterisks indicate events of $M_{L} \geqslant 2.5$. 

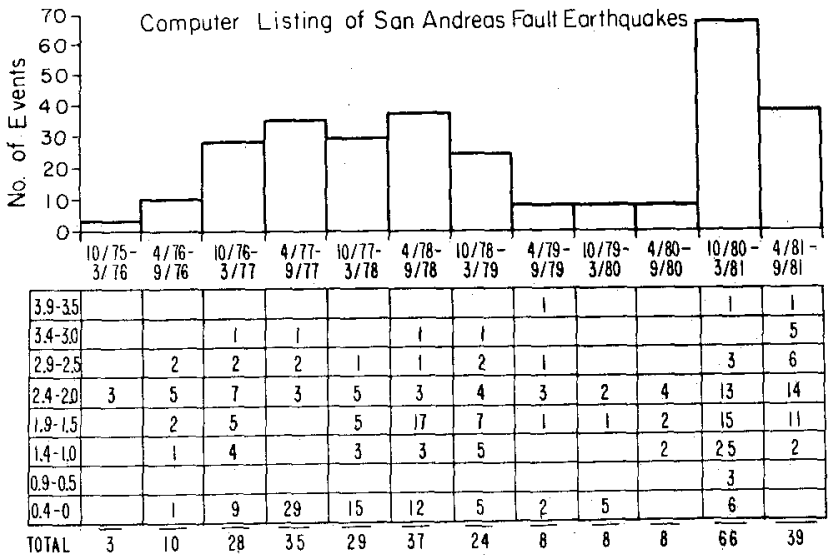

Fig. 3. Computer listing of San Andreas fault earthquakes from October 1, 1975, to September 30, 1981. The table gives the number of events per $1 / 2$ unit $\mathrm{M}_{\mathrm{I}}$ magnitude for each 6-month period. The events tabulated are those which occurred in boxes A and B (Figure 1). The graph on the upper portion of the figure shows the total number of events per 6-month period.

\section{Focal Mechanisms}

Method and Results

To examine the possible relationship between crustal deformation and earthquake mechanism in the region along and adjacent to the big bend of the San Andreas fault, $P$-wave first motion studies for 26 events $\left(M_{T} \geqslant 2.0\right)$ were made for the time period November 1976 through December 1980. Focal mechanisms could be determined for all but one of the 15 events of $M_{L} \geqslant 2.5$ which occurred in box $A$ (Figure 1) during this time period. Focal mechanisms were determined for events of $2.0 \leqslant M_{T} \leqslant 2.5$ either from the Juniper. Hills and Blue Ridge area. where seismic activity has been highest (events $3,5,6,7,15,20,21,22,23$, and 25, Table 1 and Figure 4) or from other areas within box A for better temporal coverage around the time when rapid crustal dilatation was reported (events 16 and 17, Table 1 and Figure 4). To determine the focal mechanisms, arrival times and first motions were first read from computer-stored seismographic traces from the Caltech Earthquake Detection and Recording (CEDAR) system or, for events prior to June 1978, from 16 $\mathrm{mm} /$ develocorder film viewed at a scale of $1 \mathrm{~s} / \mathrm{cm}$. These data were supplemented by readings from the mobile trailer array and paper helicorder records. The events in this study were located using the computer program HYP078 with a horizontally layered crustal model. The model used was 5.5 $\mathrm{km} / \mathrm{s}$ for depths 0 to $5.5 \mathrm{~km}, 6.3 \mathrm{~km} / \mathrm{s}$ for depths of 5.5 to $16.0 \mathrm{~km}$ and $6.7 \mathrm{~km} / \mathrm{s}$ for depths 16.0 to $33.0 \mathrm{~km}$ [Hadley and Kanamori, 1977]. After locating, reduced travel time $(T-\Delta / 6.0)$ was plotted versus distance, $\Delta$, for various azimuth ranges. An interpretation of each plot was made in terms of the laterally varying Hadley-Kanamori model and station corrections from Raikes [1978]. Trave1 time information was then used to individually assign takeoff angles for each station, using the method of Pechmann [1979].

TABLE 1. Events Selected for First Motion Studies

\begin{tabular}{|c|c|c|c|c|c|c|c|c|}
\hline Event & Date & & Time & $\begin{array}{c}\text { Local } \\
\text { Magnitude }\end{array}$ & Latitude & Longitude & $\begin{array}{l}\text { Depth, } \\
\text { km }\end{array}$ & $\begin{array}{l}\text { No. of } \\
\text { Stations }\end{array}$ \\
\hline 1 & Nov. 3 , & $1976 *$ & 1741 & 2.6 & $34^{\circ} 31.11$ & $117^{\circ} 46.40$ & 10.1 & 15 \\
\hline 2 & Nov. 7 , & $1976 *$ & 1421 & 2.6 & $34^{\circ} 40.20$ & $118^{\circ} 33.10$ & 7.5 & 19 \\
\hline 3 & Dec. 13 , & $1976 *$ & 0826 & 2.2 & $34^{\circ} 28.56$ & $118^{\circ} 00.60$ & 8.2 & 28 \\
\hline 4 & Jan. 1 , & $1977 *$ & 0100 & 2.8 & $34^{\circ} 27.49$ & $117^{\circ} 57.69$ & 8.7 & 37 \\
\hline 5 & Feb. 14, & $1977 *$ & 0916 & 2.0 & $34^{\circ} 28.63$ & $117^{\circ} 51.64$ & 3.8 & 16 \\
\hline 6 & Feb. 27, & 1977 & 1448 & 2.3 & $34^{\circ} 28.37$ & $117^{\circ} 57.37$ & 8.7 & 19 \\
\hline 7 & Mar. 5, & 1977 & 1443 & 2.1 & $34^{\circ} 27.78$ & $117^{\circ} 57.69$ & 9.6 & 13 \\
\hline 8 & Mar. 7, & $1977 *$ & 1.104 & 3.0 & $34^{\circ} 27.68$ & $117^{\circ} 58.18$ & 9.1 & 28 \\
\hline 9 & Mar. 23, & 1977 & 0515 & 2.5 & $34^{\circ} 27.94$ & $117^{\circ} 57.71$ & 7.5 & 17 \\
\hline 10 & Sept. 6, & $1977 *$ & 0508 & 3.0 & $34^{\circ} 27.95$ & $117^{\circ} 57.93$ & 8.7 & 24 \\
\hline 11 & June 19 , & $1978 *$ & 0741 & 3.0 & $34^{\circ} 37.07$ & $117^{\circ} 45.02$ & 7.6 & 40 \\
\hline 12 & July 12, & 1978 & 1323 & 2.5 & $34^{\circ} 25.67$ & $117^{\circ} 50.17$ & 5.9 & 23 \\
\hline 13 & Nov. 7 , & 1978 & 0028 & 2.6 & $34^{\circ} 39.91$ & $118^{\circ} 24.08$ & 12.4 & 15 \\
\hline 14 & Jan. 21, & 1979 & 1611 & 3.1 & $34^{\circ} 39.35$ & $117^{\circ} 44.54$ & 6.4 & 36 \\
\hline 15 & Feb. 17, & 1979 & 1236 & 2.0 & $34^{\circ} 28.23$ & $118^{\circ} 04.37$ & 11.6 & 12 \\
\hline 16 & Mar. 9, & 1979 & 2231 & 2.4 & $34^{\circ} 41.62$ & $117^{\circ} 53.85$ & 1.8 & 12 \\
\hline 17 & Apr. 18, & 1979 & 0311 & 2.4 & $34^{\circ} 45.26$ & $118^{\circ} 46.98$ & 12.1 & 21 \\
\hline 18 & Aug. 28, & 1979 & 0857 & 3.9 & $34^{\circ} 25.16$ & $117^{\circ} 44.62$ & 7.8 & 62 \\
\hline 19 & Aug. 29, & 1979 & 1420 & 2.5 & $34^{\circ} 25.26$ & $117^{\circ} 44.34$ & 8.0 & 31 \\
\hline 20 & Aug. 30 , & 1979 & 0208 & 2.0 & $34^{\circ} 25.33$ & $117^{\circ} 44.63$ & 8.6 & 13 \\
\hline 21 & Sept. 3, & 1979 & 0006 & 2.0 & $34^{\circ} 25.11$ & $117^{\circ} 44.90$ & 8.0 & 15 \\
\hline 22 & oct. 24 , & 1979 & 0742 . & 2.0 & $34^{\circ} 25.00$ & $117^{\circ} 45.12$ & 8.0 & 15 \\
\hline 23 & Apr. 27, & 1980 & 1639 & 2.4 & $34^{\circ} 28.17$ & $117^{\circ} 57.37$ & 9.0 & 21 \\
\hline 24 & oct. 13, & 1980 & 1339 & 2.7 & $34^{\circ} 22.31$ & $117^{\circ} 40.64$ & 11.3 & 19 \\
\hline 25 & Dec. 22, & 1980 & 0836 & 2.1 & $34^{\circ} 24.63$ & $117^{\circ} 40.90$ & 6.5 & 18 \\
\hline 26 & Dec. 30 , & 1980 & 0819 & 2.5 & $34^{\circ} 32.99$ & $118^{\circ} 9.29$ & 12.5 & 16 \\
\hline
\end{tabular}

*Pechmann [1979]. 


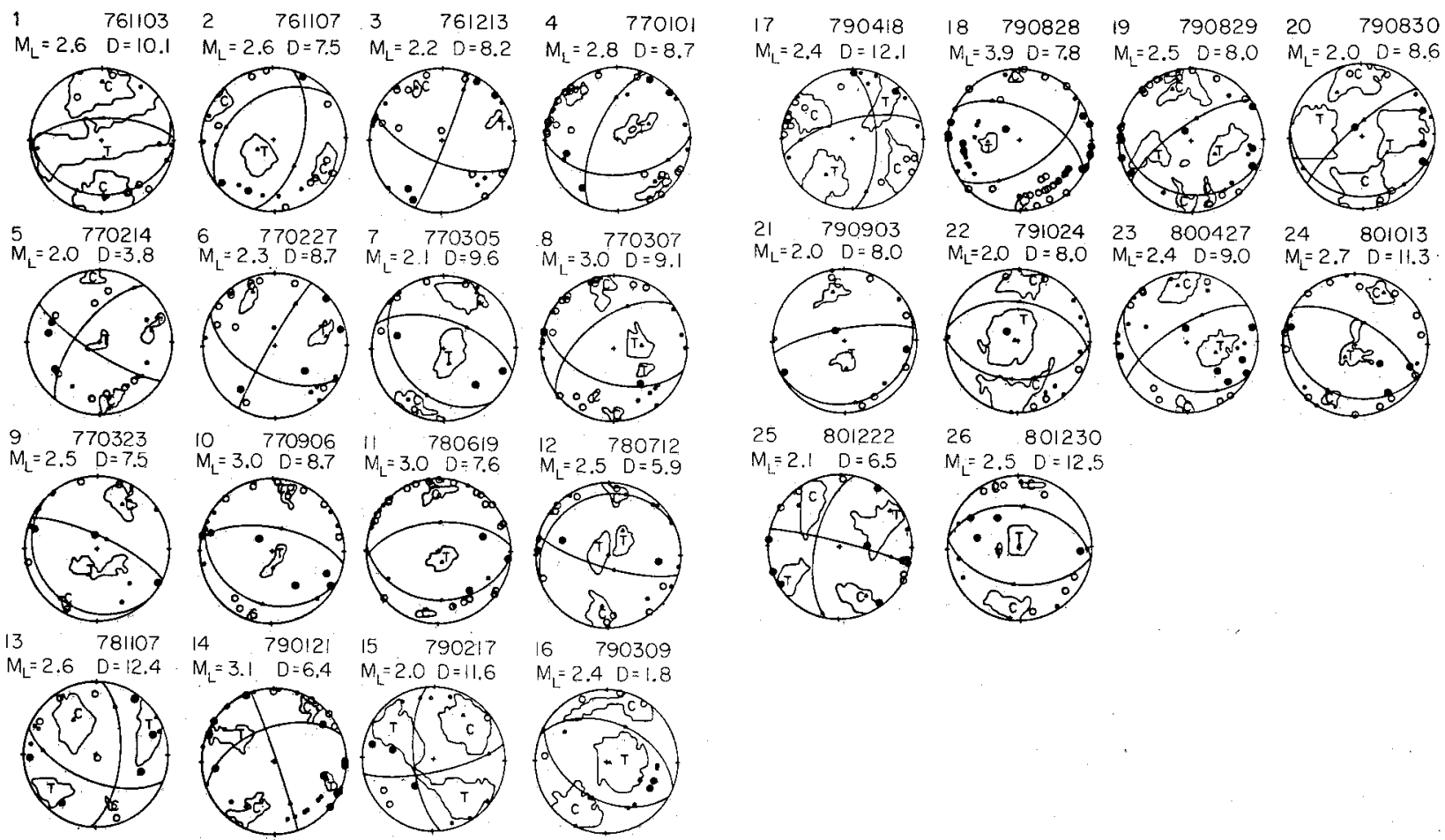

Fig. 4. Lower hemisphere P-wave focal mechanisms. M is local magnitude. $D$ is depth of hypocenter in kilometers. Open circles indicate dilatation. Solid circles indicate compression. Compression (C) and tension ( $T$ ) axes are shown as triangles. The range of possible positions for the compression (C) and tension ( $T$ ) axes are indicated by the contoured regions.

From the P-wave first motion information, nodal planes were determined with the aid of the computer program FOCPLT developed by Whitcomb and Garmany [Whitcomb, 1973]. This program tests a grid of trial mechanisms spaced at approximately 5 degree intervals on the focal sphere and then chooses a mechanism which minimizes the number of first motion readings in error. Less reliable readings are given half the weight of other readings, and a linear function is used to downweight stations within 3 degrees of a noda1 plane, Figure 4 shows the first motion plots with the nodal planes chosen by FOCPLT. To show the constraints of the data on these solutions, a range of possible positions for the compression (C) and tension ( $T$ ) axes is indicated. Compression, and tension axes within these contoured regions correspond to solutions with up to one 'good' (large circle) or two 'fair' (small circle) additional readings in error beyond the minimum. The events for which focal mechanisms were determined are listed in Table 1 , and epicenter locations are shown in Figure 5 .

$P$ and $T$ axes determined using the FOCPLT program are plotted in Figure 6. Similar to the results reported by Pechmann [1979] for the central Transverse Ranges, events near the big bend of the San Andreas fault can be characterized by horizontal $\mathrm{N}-\mathrm{S}$ compression and a near vertical tension axis. The orientation "of maximum horizontal compressive stress inferred from hydrofracture measurements [Zoback, et a1., 1980] and strain relief measurements [Flaccus et al., 1980] in the Palmdale area is roughly NNW. P axes from 50 fault plane solutions in the western
Transverse Ranges [Yerkes and Lee, 1979], however, are north to northeast trending and subhorizontal.

To compare the focal mechanisms to horizontal strain data, the strain data (J. C. Savage, personal communication, 1981) were superimposed on a time/distance plot of the seismicity (Figure 7) together with 13 of the 14 events of $M_{T} \geqslant 2.5$ plus as many additional mechanisms (from Figure 4) from smaller events which could fit on the graph. The events studied here are located primarily between two USGS trilateration networks, the Palmdale network to the northwest and the Cajon network to the southeast (Figure 5). Therefore, changes in horizontal strain in the region of the events can only be inferred. Because more frequent measurements were taken on the Palmdale network, the strain data from this network were examined in more detail. For the 1971-1980 time period, right-lateral shear strain $\left(\gamma_{2}\right)$ showed fairly uniform accumulation. The strain $(\varepsilon)$ from 1973 to 1978 was predominantly uniaxial N-S compression, whereas since that time there have been episodes of $\mathrm{N}-\mathrm{S}$ extension and an increased rate of $\mathrm{E}-\mathrm{W}$ extension [Savage et a1., 198la, b].

The results summarized in Figure. 7 show that the focal mechanisms appear to change with time for events from the same source region. This was reported by McNally et al. [1978] for the 1976-1977 Juniper Hills swarm, which was concentrated within a $3-\mathrm{km}$ source region. A systematic change from strike-slip to thrust faulting was reported during this sequence based on mechanisms for four of the larger events (events 3, 4, 8, and 10 in Figure 4). Additional mechanisms for this swarm obtained in 


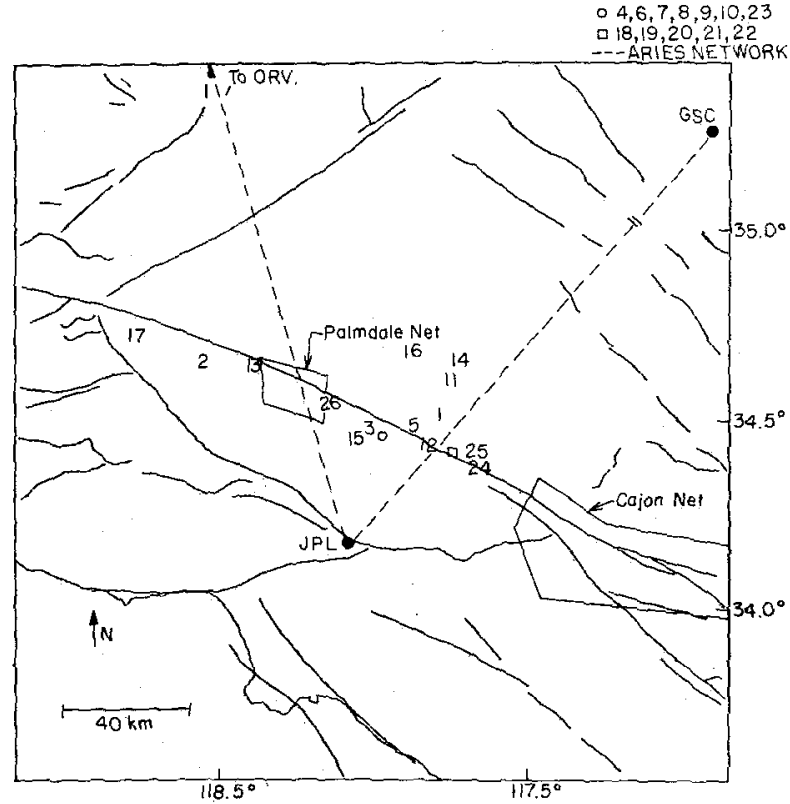

Fig. 5. Location of events for which a focal mechanism has been determined. Event numbers are as given in Table l. The location of the USGS Palmdale and Cajon trilateration networks along with the ARIES baselines are shown. JPT is the Caltech Jet Propulsion Laboratory, GSC is the Goldstone Tracking station and ORV is the Owens Valley Radio Observatory.

this study (events 6, 7, and 9 in Figure 4) confirm this pattern. The mechanism of an event which occurred $21 / 2$ years later in this same region (event 23 , Figures 4 and 7 ) shows oblique slip. During the swarm sequence, the $P$ axis rotated clockwise from northwest to north-northeast. Although the changes in faulting mechanism have not yet been adequately explained, they may be related to local rotations of principal stress axes caused by slip on a nearby fault, as proposed by Rudnicki [1979].

A less pronounced temporal pattern of change in mechanism from oblique slip to pure thrust was observed for a mainshock-aftershock sequence (events 18-22, Figure 4) near Blue Ridge which started in August 1979. Using the mainshock (August 28, 1979) as a master event, events 19-22 were relocated relative to this event. The five events in this mainshock-aftershock. sequence located within $1 / 2 \mathrm{~km}$, which is within the location resolution. First motions for this mainshock-aftershock sequence were examined to determine if the apparent change in mechanism could be verified by changes at individual stations. Station data for the August 28, 29, and 30 events were found to be similar, but a change in first motion direction for several stations occurred during the September 3 and October 24 events.

More detalled information on how tightly the 1976-1977 Juniper Hills sequence and the 1979 Blue Ridge sequence are spatially clustered could be obtained by examining the seismograms using the method of Geller and Mueller [1980]. Any systematic change in location or depth with time could be important because of the apparent temporal changes in focal mechanisms. Using the
HYp078 locations, a correlation between mechanism type and depth was not found. Since both the Juniper Hills swarm and the 1979 Blue Ridge sequence occurred. within small source regions, the temporal changes in mechanism may reflect changes in the local and/or regional stress field.

The temporal changes in focal mechanism for all the events are best seen by examining the orientations of the $\mathrm{P}$ and $\mathrm{T}$ axes (Figure 8 ). The angles $\phi_{\mathrm{P}}$ and $\phi_{\mathrm{T}}$ between the vertical and the $P$ and $T$ axes, respectively, are plotted versus time for each of the 26 events listed in Table 1. Although there is some fluctuation in $\phi_{p}$, the $P$ axis is generally horizontal to subhorizontal with no systematic changes with time. $\phi_{T}$, however, ranges from near vertical to near horizontal. There are two time periods where $\phi_{T}$ is generally greater than 45 degrees, indicating that the mechanisms are closer to strike slip than to thrust. The first period (December 1976 to February 1977) corresponds to the beginning of the Juniper Hills swarm. No strain anomaly was reported during this period, although measurements were only being taken about once a year. The second period (November 1978 to April 1979) approximately coincides in time with a change in the trend of the strain data from uniaxial N-S compression to dilatation.

\section{Discussion}

Before discussing the results of the focal mechanism study, some of the limitations of the data should be mentioned. First, many of the focal mechanisms for these small events $\left(2.0 \leqslant M_{T} \leqslant 3.6\right)$ are not well constrained. second, prior to 1979, the strain measurements were taken only on a yearly basis on the Palmdale network. Later measurements showed significant strain changes between surveys taken only a few months apart. Therefore, the strain data may not accurately indicate the real temporal changes in crustal deformation because of aliasing problems. Furthermore, strain changes between individual measurements on the Palmdale network from 1976 to 1978 are not statistically significant, although the general trend of uniaxial N-S contraction from 1971 to 1978 does appear significant [Savage et a1., 1981a]. For these reasons, it is not possible to define the time of onset of relative

- Compression

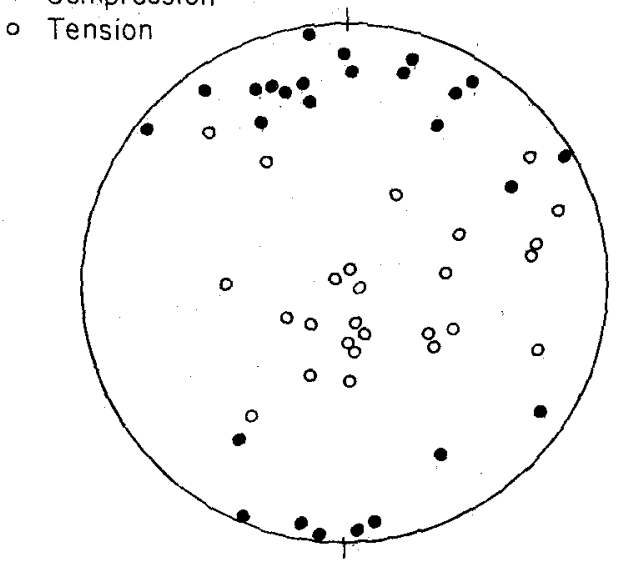

Fig. $6 . P$ and $T$ axis for events in Figure 4. 


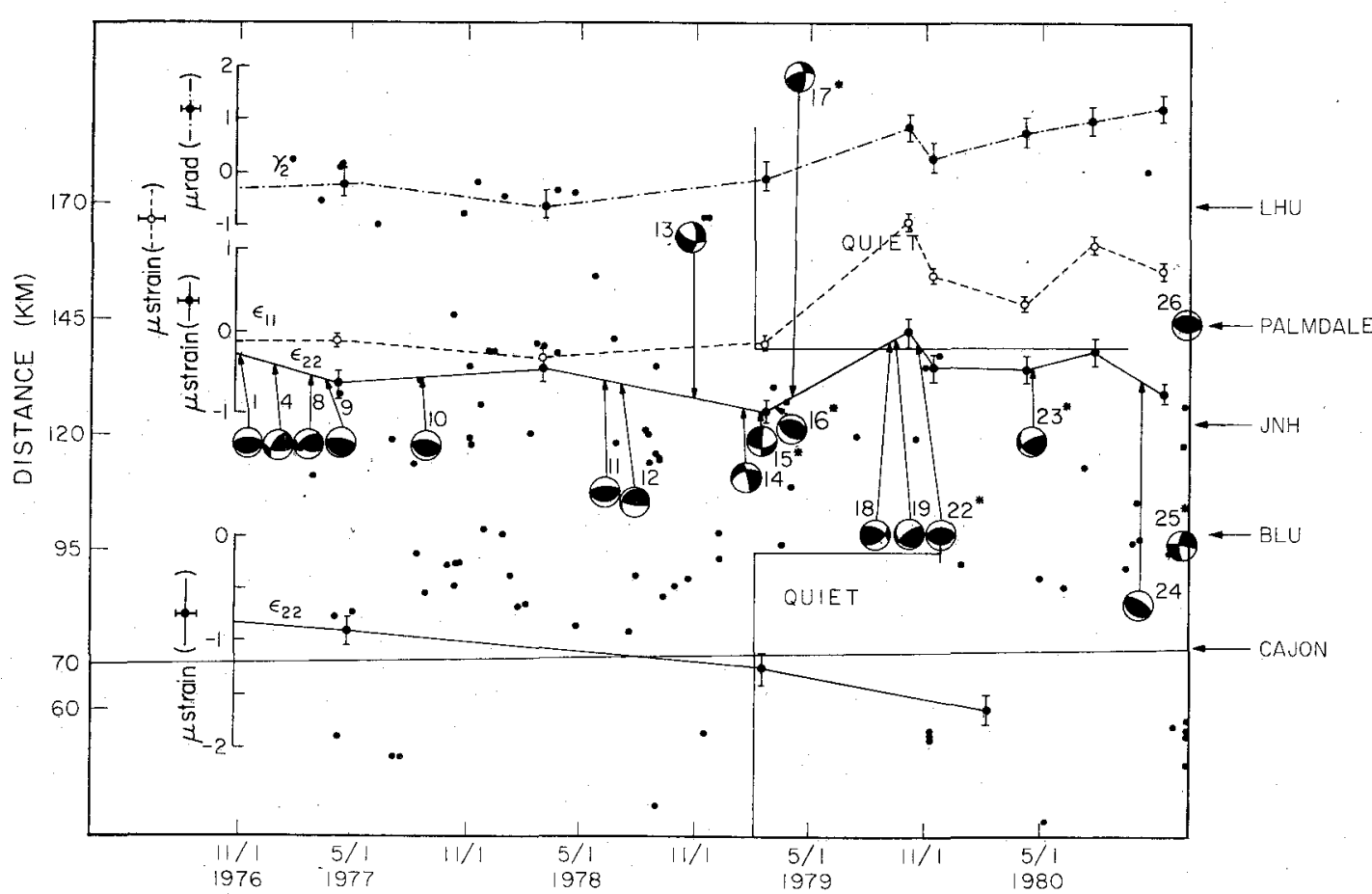

Fig. 7. Time/distance plot of seismicity with strain data and focal mechanisms superimposed. The top three graphs are strain data from the Palmdale network. Strain accumulation in the Palmdale network is referred to a coordinate system in which the 1 axis is $\mathrm{E}-\mathrm{W}$ and the 2 axis is $\mathrm{N}-\mathrm{S}$. The error bars represent one standard deviation on either side of the plotted point; $\gamma_{2}$, engineering shear strain (twice the tensor shear strain), right-lateral strain accumulation is positive; $\varepsilon_{11}$, E-W strain, compression is downward; $\varepsilon_{22}, \mathrm{~N}-\mathrm{S}$ strain, compression is downward. The bottom graph is $\mathrm{N}-\mathrm{S}$ strain from the Cajon network. The positions of the focal mechanisms correspond (as closely as possible) to their temporal and spatial location on the graph. Their ocurrence in time is more closely indicated by the arrows pointing to the $\mathrm{N}-\mathrm{S}$ strain data. An asterisk appears next to the focal mechanisms for events of $2.0 \leqslant M_{L}<2.5$.

dilatation in late 1978-1979 to within better than approximately \pm 6 months, or to know if the subsequent period of compression began before or after the October 1979 survey (Figure 7). Thus, although the second group of strike-slip earthquakes (November 1978 to April 1979) appears to be roughly concurrent with the dilatation, a temporal coincidence cannot be conclusively proven or disproven with the data at hand.

In the area around the big bend of the San Andreas fault the most compressive principal stress is roughly N-S. Anderson's [1951] theory of faulting predicts strike-slip failure for this region if the intermediate principal stress is vertical and the least principal stress is $\mathrm{E}-\mathrm{W}$. Thrust events can occur if the least principal stress is vertical and the intermediate principal stress is $\mathrm{E}-\mathrm{W}$. Therefore, a change in mechanism from thrust to strike slip suggests that the least principal stress has changed from vertical to horizontal E-W. Although Anderson's theory does not take into account preexisting zones of weakness, the variations in mechanism suggest that a wide variety of potential fault surfaces exists regionally and that small earthquakes occur on those most favorably oriented to the current stress field.

The change in mechanism from thrust (events II and 12, Figures 4, 7, and 8) to predominantly strike slip (events 13, 14, 15, and 17, Figures 4, 7 , and 8) during the period mid-1978 to mid-1979 is at last qualitatively consistent with the measured horizontal strain changes and may reflect a change in the tectonic stress field. The $E-W$ extension which began in 1978-1979 could cause a rotation of the least principal stress axis from near vertical to near horizontal, depending on the preexisting stress and the magnitude and sign of any changes in the vertical stress component. Although $\mathrm{N}-\mathrm{S}$ extension was also observed at this time, it was smaller in magnitude than the $\mathrm{N}-\mathrm{S}$ compressive strain accumulated over the previous 7 years, and hence the orientation of the greatest compressive principal stress probably remained approximately $\mathrm{N}-\mathrm{S}$.

A decrease in the level of seismic activity and a change in the predominant type of mechanism to more strike-slip motion around the time when there is a change from relative compression to dilatation suggests that regional strain changes might influence small earthquake faulting. The maximum linear strain change observed on the Palmdale network is $1.5 \mu$ strain. If we assume a linear relation between stress and strain and take the elastic modulus to be $3.3 \times 10^{11} \mathrm{dynes} / \mathrm{cm}^{2}$, this strain change roughly corresponds to a stres change of 0.5 bar. Changes in the level of microearthquake activity and a change in the predominant type of fault mechanism might therefore occur as a result of small changes in stress. However, the data are incomplete, and further monitoring is necessary to substantiate this conclusion. 


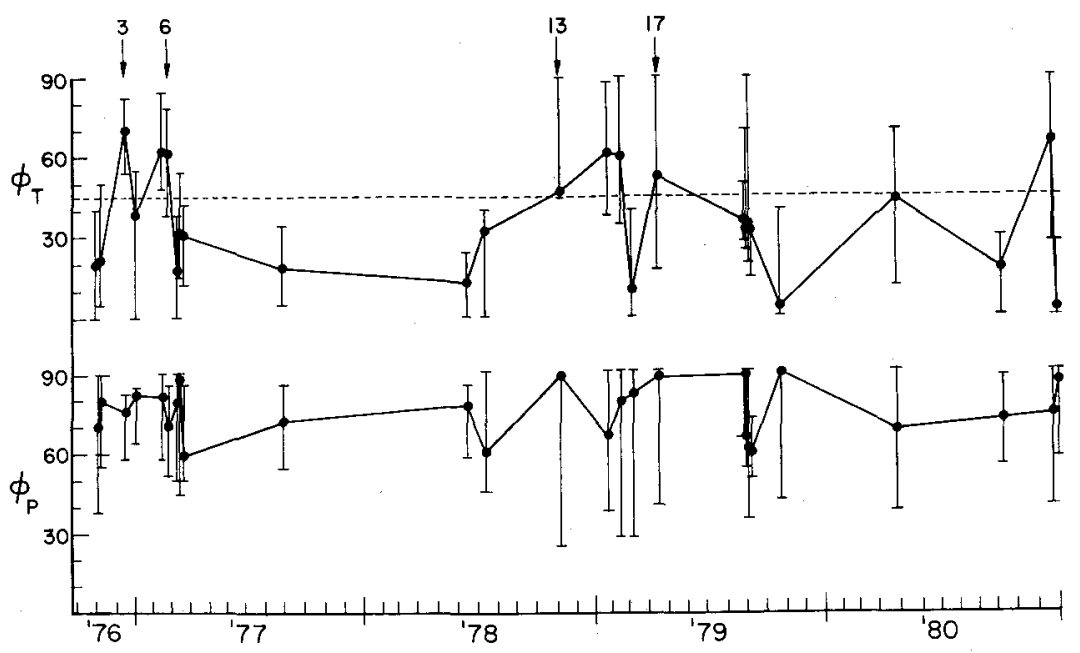

Fig. 8. The angle $\phi_{\mathrm{P}}$ and $\phi_{\mathrm{T}}$ between the vertical and the $\mathrm{P}$ and $\mathrm{T}$ axes, respectively, plotted against time for each of the 26 events listed in Table 1 . The error bars correspond to the range of possible angles for the $P$ and $T$ axis with up to one 'good' or two 'fair' additional readings in error as shown in Figure 4.

\section{Conclusions}

Increased microearthquake activity which began in November 1976 along the big bend portion of the San Andreas fault continued through 1978. Around the beginning of 1979 , microearthquake activity to the NW and $S E$ of the Juniper Hills area abruptly decreased. This change in seismicity occurred around the time of rapid dilatation reported by P. F. MacDoran et a1. (unpublished data, 1980) and Savage et a1. [1981].

Focal mechanisms from the study region are predominantly thrust type. There are two time periods when the mechanisms are closer to strike slip than to thrust. The first period (December 1976 to February 1977) corresponds to the beginning of the Juniper Hills swarm. The second period (November 1978 to April 1979) approximately coincides with a change in trend of the strain data from uniaxial N-S compression to dilatation.

Acknowledgments. We thank J. C. Savage and P. MacDoran for supplying data in advance of publication; Carol Bryan for her assistance in determining some of the focal mechanisms; Roger Bowman, Bill Stuart, Lynn Sykes, and an anonymous reviewer for their critical reading of the manuscript. This work was supported by U. S. Geological Survey contract 14-08-0001-19266 and by the Earth Sciences section, National Science Foundation grant EAR 78-05352. Contribution 3677, Division of Geological and Planetary Sciences, California Institute of Technology, Pasadena, California 91125.

\section{References}

Anderson, E. M., The dynamics of faulting, 206 pp., 01iver and Boyd, Edinburgh, 1951.

Drowley, D. S., and K. C. McNally, Location of earthquake swarm events near Palmdale, California, using a linear gradient velocity model, Bull. Seismol. Soc. Am., 70, 2145-2158, 1980 .

Flaccus, C. E., R. M. Richardson, M. L. Sbar, T. Engelder, and D. Yale, Tectonic stress near the San Andreas fault from strain relief measurements, Eos Trans. AGU, 61, 1118, 1980. Geller, R. J., and C. S. Mueller, Four similar earthquakes in central California, Geophys. Res. Lett., 7, 821-824, 1980.

Ha dley, D., and H. Kanamori, Seismic structure of the Transverse Ranges, California, Geol. Soc. Am. Bu11., 88, 1469-1478, 1977.

McNa11y, K. C., H. Kanamori, J. C. Pechmann, and G. Fuis, Earthquake swarm along the San Andreas fault near Palmdale, southern California, 1976 to 1977 , Science, $201,814-817,1978$.

Pechmann, J.C., Tectonic implications of small earthquakes in the central Transverse Ranges, U. S. Geol. Surv. Prof. Pap., in press, 1979. Raikes, S., Regional variation in upper mantle compressional velocities beneath southern California, Ph.D. dissertation, part I, Calif. Inst. of Technol., Pasadena, 1978, pp. 53-56.

Rudnicki, J. W., Rotation of principal stress axes caused by faulting, Geophys. Res. Lett., 6 , $135-138,1979$.

Savage, J. C., W. H. Prescott, M. Lisowski, and N. E. King, Strain accumulation in southern California, 1973-1980, J. Geophys. Res., 86, 6991-7002, 1981a.

Savage, J. C., W. H. Prescott, M. Lisowski, and N. E. King, Strain accumulation on the San Andreas fault near Palmdale, California: Rapid, aseismic change, Science, 211, 56-58, $1981 \mathrm{~b}$.

Whitcomb, J. H., The 1971 San Fernando earthquake series focal mechanisms and tectonics, Ph.D. dissertation, part II, Calif. Inst. of Techo1., Pasadena, 1973, pp. 254-269.

Yerkes, R. F., and W. H. K. Lee, Late Quaternary deformation in the western Transverse Ranges, California, U. S. Geol. Surv. Circ., 799-B, 11 pp., 1979.

Zoback, M. D., H. Tsukahara, and S. Hickman, Stress measurements at depth in the vicinity of the San Andreas fault: Implications for the magnitude of shear stress at depth, J. Geophys. Res., 85, 6157-6173, 1980.

(Received August 7, 1981;

revised August 3, 1982;

accepted September 8, 1982.) 